\title{
The Impact of Communication Technologies on the Performance of SMES IN A DEVELOPING ECONOMY: NIGERIA AS A CASE STUDY
}

\author{
Ibrahim Adeniyi Rufai \\ University of Birmingham \\ UK \\ mutiat_rufaiadeleke@yahoo.com
}

\begin{abstract}
Informed by Social Shaping Theory (modified), this paper presents a research that examines the impact of communication technologies (mobile telephony, personal computer and internet facilities) on the performance of small and medium businesses in Lagos state, Nigeria. Results indicate that SMEs operating in different socio-economic settings present varying performance results from the use of communication technology tools. The study was undertaken through a firm survey and also a number of semi-structured interviews with purposively selected 100 SMEs operating in both the affluent and disadvantaged districts of the city. Using basic descriptive statistics and thematic analytical techniques for the survey and interview data respectively, major findings suggest that: 1) as communication technologies positively impact the performance of SMEs, existing socio-economic factors within the districts where the firms operate also influence the choice of communications technology and significantly shape its impact on business performance; 2) class differences with respect to income and education disparity, as well as communication habits in the affluent and disadvantaged communities account for different outcomes in the business performance of firms; 3) the Impact of communication technologies on the local economy seems to be more prominent and significant in regard to the performance of firms operating in the affluent districts compared to the performance of firms operating in disadvantaged districts
\end{abstract}

\section{INTRODUCTION}

Globally, entrepreneurs and other stakeholders now seem to have fully come to terms with the transformational impact of ICT for rapid improvement in economic and social welfare. It is now credited with facilitating access to numerous health services, learning materials, education and works to beneficiaries wherever they may be (Broadband Commission, 2013). The Broadband Commission report also indicated that mobile subscription in Africa and the Middle East exceeded one billion in 2013. It predicted there could be over 2.1 billion mobile broadband subscriptions in 2014, about one third of the global stock of mobile technologies up from one fifth in 2011 (ITU website, 2014). The subscription level s projected to reach 7 billion in 2018.

According to (Budde Communications (2013): cited in Broadband Commission Report, (2013), “Africa is the region with the largest remaining growth potential in the world and it is estimated that the market in telecom services will grow by 1.5 billion people, almost half the remaining market worldwide, by 2050" (ITU website, 2014). The report also indicated that much of the growth in fixed broadband subscriptions globally is located in developing economies. However, it is stated that the overall fixed broadband penetration rates still remain low at $6.1 \%$ in developing countries, compared with $27.2 \%$ in industrialised nations in 2013 (ITU website, 2014).

Mobile telephony penetration in Africa sub-continent is now reported the highest in the globe, accounting for over 620 million subscribers, second only to Asia (Atkearney and GSMA, 2011). Its contribution to socio-economic well-being and business development has been widely noted. According to (Jeffrey (2010): cited in Etzo and Collender, (2010)), 
“mobile phones are the single most transformative technology for development” (p.661). It is reported as having capacity to support democratic values in the form of voters' enlightenment (Aker et al., 2013), curtail corruption tendencies (Bailard, 2009) and facilitate socioeconomic growth and development (Okpaku, 2006).

According to Aker and Mbiti (2010), "As telecommunication markets mature, mobile phones in Africa are evolving from simple communication tools into service delivery platforms. This has shifted the development paradigm surrounding mobile phones from one that simply reduces communication costs to one that could transform lives through innovative applications and services” (p.208).

In the context of the above, SMEs operating within the African markets have huge possibilities to lower their costs, increase productivity and revenue generation drive by leveraging on the business transformational potentials of communication technologies. According to (McKenzie (2012): cited in Broadband Commission Report, (2013) ), "SMEs which invest more than $30 \%$ of their budget on web technologies can grow their revenue nine times as fast as SMEs spending less than 10\%” (ITU website, 2014).

However, ICTs in general, and mobile telephony in particular, are also accused of promoting poverty and reinforcing socio-economic disconnection. Puri et al. (2010) noted instances in some African Millennium villages where dwellers prefer to forgo payment of their children's school fees in preference for purchasing mobile phones credit. In Ethiopia, the economically disadvantaged $75 \%$ of the country's total population with mobile telephony subscription and usage expend about one-third (27\%) of their wages on it, showing "the continued high cost of services on the continent" (Gillwald and Stork, 2008, p.14). This probably depicts that some individuals believe so much in the socio-economic utility of mobile telephony, and are willing to expend a high proportion of their disposable income for its services. However, accusing ICT of engendering poverty by itself seems unfairly exaggerated. Varying socio-economic circumstances of users and other unknown intervening variables might provide plausible explanations concerning how ICT's benefits are distributed and perceived by different consumers.

Fuchs and Horak (2008) state thus "unequal pattern of material access, usage capabilities, benefits and participation concerning ICTs are also due to the asymmetric distribution of economic (money, property), political (power, social relationships), and cultural capital (skills)" (p. 101). Therefore, impact of ICTs in general and mobile telephony in particular should be analysed and examined in the context of prevailing socio-economic factors and forces which are either strengthened or weakened by them (ICTs). ICTs or mobile telephony would either serve as tools/catalysts of socio-economic empowerment or instruments of socio-economic domination and exploitation, depending on the context of usage. They embed in the prevailing context of social support, resource extraction and conflict, and also contribute to reconfigure and reconstitute them (Carmody, 2010).

The overarching theme of this article suggests that while communication technologies could boost performance of SMEs in developing economy, prevailing socio-economic factors and circumstances within the districts where firms operate significantly shape such influence, and might account for varying outcomes in the business performance of different firms. Hence, developmental efforts should go beyond ensuring universal, equal access to ICTs, but also marshalling the machinery of government through policy initiatives to facilitate, enhance and support local capacity for effective usage of ICT tools to achieve socio-economic objectives.

The rest of this paper is structured to present a review of relevant literature relating to ICTs impact studies and SMEs business performance. This is followed by theoretical underpinning of the work and the justification for social shaping theory as the most 
appropriate framework for the study. Methodological issues are later articulated, followed by discussion and conclusion of the study.

\section{LITERATURE REVIEW}

The potential of ICT as agent of international trade and socio-economic development in today's increasingly deregulated world's economy has been widely noted (Jelessi, 2009). Van Dijk (2006) highlighted the effectiveness of ICT as a potent driver of economic development in South Korea as well as other South-East Asian nations. Also, Burke (2010) explained that ICT deployment (i.e ownership of websites) serves as a major boost to increased sales volume and new customers' acquisition drive by firms.

Further, Kamal and Qureshi (2009) indicated a positive relationship between ICT usage and SMEs growth, development and sustainability. ICT is also perceived to be a lifesaving intervention for ailing small and medium businesses. It is thought ICT possesses inherent capabilities that could bolster the survival chances of small firms (Good and Qureshi, 2009; Kamal and Qureshi, 2009).

According to the United Nations (2007), ICTs' adoption can be very beneficial to SMEs performance. Such potential performance-enhancing benefits include: increased productivity in the production processes; improved efficiency of internal business operations; better and accelerated access to domestic and global business contacts; improved inventory management systems; efficiency in production processes; improved intra-departmental communication; improved accounting and budgeting practices; significant communication cost reduction; increased client base through e-marketing; facilitating links to domestic and global outsourcing contacts; facilitating acquisition of best practices in business dealings; facilitating capacity-building of entrepreneurs and workforce through e-learning platforms as well as enabling business registration and administration of tax remittances. Also, the European Commission (2008) echoes similar sentiment that ICT is capable of enhancing growth potentials of SMEs and accelerating their innovativeness.

The positive influence of ICT usage on business performance of SMEs has also been widely reported in a significant number of empirical studies. It (ICT) is viewed as a catalyst to organisational change (Hazbo et al., 2008) and an enabler to improved business performance of SMEs. Evans and Wurster (1997) argue that it facilitates reach and engenders richness in e-business communication and collaboration with stakeholders, as well as enhances the capacity of local SMEs to engage gainfully in the digital economy (Golding et al., 2008). Pavic et al. (2007) reported that SMEs could leverage on ICT advances to gain competitive advantage in terms of innovation, marketing, business efficiency, product quality and customers' responsiveness. Also, empirical findings from a study by Frank and Wallace (2012) on 'The Livelihood Outcomes of ICT Use in Microenterprises: The Case of South Africa' suggest a positive impact of ICT on the livelihoods of small and medium firms. "Overall, the effects of using ICT were easy communication and time saving when interacting with customers and suppliers" (Frank and Wallace, 2012:10).

Rim's (2009) analysis of secondary survey data set (covering different manufacturing sectors between 1998 - 2002) obtained from Tunisian National Institute of Statistics (TNIS) relating to its National Annual Survey Report of Firms (NASRF) indicated a strong impact on firms' efficiency as a consequence of ICT use. Firms/organisations with more relative deployment/usage of ICT were reported to enjoy an average 5\% productive efficiency than their contemporaries. Besides, it was found that ICT deployment/usage complemented with right human capital investment would improve firms' efficiency far more beyond the direct influences of these two factors (ICT and Human Capital) if isolated.

Causal relationship between mobile telephony in particular and productive efficiency was also demonstrated by Thompson and Garbacz (2007). Their finding established a 
positive effect of telecommunication - mobile telephony on productive efficiency in developing countries. Samuel et al., (2005), in their study which appeared in a Vodafone report study tagged Africa: The Impact of Mobile Phones (2005) also reported that people use mobile technology as a substitute for travel, for business transactions - to start and open business, and to strengthen social bond with friends and family.

A more recent study of impact of ICT on small and medium enterprises in Kumasi, Ghana suggests that most of the SMEs studied experienced a positive business performance as well as other benefits, as a result of using ICT. The study (Akomea-Bonsu, 2012), a mixed-method investigation of 40 SMEs specifically reported a significant increase in sales volume as a result of using the internet/website; cost reduction and improvement in business operations and increase in firms' output/productivity. A related study (Oluwatayo, 2012) on a random sample of 350 small scale business owners in Southwest Nigeria concerning Information and Communication Technologies as Drivers of Growth: Experience from Selected Small Scale Businesses in Rural Southwest Nigeria, reported cost reduction, ease of marketing and enhanced incomes by small scale entrepreneurs as consequences of ICT adoption and usage.

Adewoye et al. (2012) also reported a significant and positive effect of ICT's investment on the profitability of SMEs in Nigeria. Their investigation examined the effects of Information and Communication Technology investment on the profitability of 60 randomly selected sachet water businesses in Oyo state, Nigeria. Findings suggest a significant causal relationship between ICT investment and profitability of the firms. Results also indicate an increase in manpower requirement, salary and business capital invested after ICT adoption. However, there was also a corresponding increase in production volume and profitability (Adewoye et al., 2012).

In another study, Barrantes et al. (2012) conducted an explorative, qualitative case study of the impact of mobile telephony usage on small and medium businesses in the carpentry and cabinet-making sector in a disadvantaged district of South Lima, Villa El Salvador, Peru. Informed by the cluster theoretical perspective, the research suggests that the impact of mobile telephony usage manifests more in business areas of marketing and customer relationship management. Specifically, findings demonstrate that: "the mobile telephone facilitates the rapid flow of information in the vertical negotiation processes. The mobile also improves emergency responses or furniture production impasses with bespoke design” (Barrantes et al., 2012: p.88).

Just like much of the empirical research and other theoretical arguments previously discussed in this article, these studies have made significant contributions towards our understanding of the relationship between communication technologies and society. However, their analyses focus so much on technological imperatives as determinants of socio-economic change, thereby providing an incomplete account of the relationship. A balanced explanation would need to give due considerations to both technological and social factors in the analysis in order to deepen and strengthen our understanding of a more symbiotic interaction between technology and society.

Therefore, this study departs from the prevailing perspective of technological determinism which underpins many of previous studies. Informed by the modified social shaping theoretical framework, this research investigates the impact of communication technologies (mobile telephony, internet and/or computer) on the performance of small and medium businesses operating in both the affluent and disadvantaged districts of Lagos state, Nigeria. It aims at furthering the scope of investigation in this field by providing much deeper insights and understanding into a more symbiotic and mutually-influencing relationship between technology and society. 
The research addresses the following questions:

1. What impact(s) do ICTs have in enhancing the business performance of SMEs?

2. In what ways does socio-economic context influence the choice of ICTs by SMEs; and what is the impact on business performance?

3. What are the different SME outcomes that can be identified in varying local socioeconomic contexts where there is similar ICT access; and how can these be explained?

\section{THEORETICAL FRAMEWORK}

Theoretical and academic debate on the nature of relationship between technology and society has always been intense. Many of the earliest investigations (i.e Barrantes. et al., 2012; Adewoye et al., 2012; Oluwatayo, 2012; Rim, 2009; Hazbo et al., 2008) tended to privilege technological determinism - technology viewed as an autonomous, separate entity that is independent of society and exacting effects on society. This thinking has been widely criticised as having potential to stifle creative engagement with technology, leading to uncritical embracing of technological change and defensive adaptation to it (Mackenzie and Wajcman, 1999).

By stressing technological influence on society, deterministic assumption overlooks the Social Shaping of technology or how the social relations and networks forged by individuals in society affect, moderate and shape technological impact, design and usage. Constructionism, as a general theoretical viewpoint against technological autonomy or supremacy opposes determinism.

Williams and Edge (1996) noted that social shaping of technology thinking denies that technology emanates from "a single social determinant, or through the unfolding of a predetermined technical logic” (pg.54). Sproull and Keisler (1991) established that the significant impacts of technological usage could hardly be anticipated, according to their investigation of technology usage in organizations.

However, this study modifies the Social Shaping Theory, reinforces it with a new concept of 'Symbiotic Interactionism', and adapts it for the investigation. Essentially, 'Symbiotic Interactionism' suggests a much clearer hybrid of the main ideas of technological determinism and social shaping theoretical perspectives in a mutually-influencing relationship. The modified social shaping perspective, when described with the new concept argues for 'mutually-influencing inter-activity' in explaining the relationship between technology and society - the interaction/relationship between technology and social relations/context is mutually influencing. As technology impacts society and institutions within it (technological determinism), prevailing factors in the social contexts/relations also influence technological choice, and shape its impact in change process (social shaping).

\subsection{Appropriateness and Relevance of a Social Shaping Theoretical Perspective to this Study}

Some writers and researchers (for example Winner, 1993; Bijker, 1995) interpret and think of social shaping as operating only in the design, development and production of technologies in the design and production of technologies according to certain social values and preferences, but not the selection, adoption and adaptation of the existing technologies to different community needs.

However, social shaping also applies to adaptation and selection of the existing technologies (i.e communication technologies) by different communities according to their specific prevailing socio-economic and infrastructural circumstances. Social shaping extends beyond the design and production of technologies, to exploring how social outcomes are achieved in the selection and adoption of technology. Therefore, social shaping research encompasses myriad of different social situations, circumstances and processes of technology 
adoption and selection, from design and development through production and usage, as well as the mediating influence of socio-economic forces (Williams and Edge, 1996).

\section{MeTHODOLOGY}

\subsection{Justification For Adopting Nigeria As Case Study Within Developing Economies and Sub-Saharan Africa}

According to the latest figures in the World Bank Economic Report, Nigeria is currently the biggest economy in the entire African continent, and boasts of an estimated population of 170 million - about 70\% of this lives in abject poverty (Lamido, 2014).

It accounts for almost half (47\%) of the West Africa's population, and is among the top eight countries with highest population in the globe (Internet World Stats, 2010). It is one of the world's major oil producers of crude oil and the biggest in Africa (Ploch, 2011). Much of the West Africa's economic transactions are warehoused in the country. It occupies a central and influential position as the economic and military superpower of the continent, always playing prominent roles in socio-economic and political stability of African countries (i.e. its mediating and stabilizing roles in civil/political unrest in Liberia, Sierra Leone, Zaire (DRC), Tanzania, Angola, Chad etc.). Nigeria is also a "leading player in the African Union, the New Partnership for Africa's Development (NEPAD), and the Economic Community of West Africa States (ECOWAS)” (World Bank, 2013).

The country is arguably credited with the fastest growing telecommunication market in the continent, owing to the government liberalisation programme in the telecommunication sector. Its mobile telephony subscription base is currently over 70 million, largest in Africa. Nigerians actively using mobile telephony have grown astronomically in number, but landline subscription and usage in the country has dropped (Charles et al., 2007). The growth in the telecommunication sub-sector has positively inspired and impacted entrepreneurship, leading to increasing opportunities for small and medium businesses in the form of franchises, retailer ships, dealership and other associated value added services (Tella et al., 2007).

Therefore, in addition to other factors mentioned in this narrative, the choice of Nigeria as a case study and representation of developing economies and Sub-Saharan Africa is informed by its strategic position as a regional and continental economic superpower within Africa. It is thought that the research outcomes/results would give an indication of the trend, as well as inform ICT policy design in other African/developing countries with similar political, cultural and socio-economic situations/circumstances, with respect to the potential impact of communication technologies on the performance of small and medium businesses operating in different context - the affluent and disadvantaged districts.

\subsubsection{Study Area: Profile of Lagos State, Nigeria}

In landmass, Lagos state is one of the smallest states in Nigeria - accounting for 356, 861 hectares, out of which 75,755 are wetlands. It is the most populous state in Nigeria. Every ethnic nationality in the country is represented in Lagos state (Oladeji and Roberts, 2001, pg.1). The Yorubas constitute about 60\%, while Hausa, Igbo and other ethnic minorities account for about $40 \%$ of its population.

Despite being one of the most expensive cities in the globe, most Lagosians live in abject poverty by local and international standards. Majority of its disadvantaged populace reside in low-cost, highly populated areas of the city such as: Bariga, Agege, Ajegunle, Isolo, Oshodi, Shomolu, Shogunle, Mushin and so on. Large sections of these areas sometimes in appalling sanitary conditions, but are relatively convenient to industrial employment or amenable to self-employment (Peil, 1991). 
There is however a considerable number of rich residents who choose to live among their kinsmen in low-income, crowded areas "from Lagos Island and Ajegunle to Agege and other northern suburbs. This is partly a question of where successful men have found land to build and partly the need to stay close to business interests or the desire to remain with kinsmen” (Peil, 1991, p.26).

The number of blights/slums inhabited by the low-income residents of Lagos has been on the increase since 1980s. The state government acknowledged 42 of such blighted neighbourhood in 1983. Results of a survey conducted by Omirin and Nubi (2006) established that over 70 percent of metropolitan Lagos is blighted.

Ikoyi, Victoria Island and Lekki Peninsula which are all within the boundaries of EtiOsa Local Government area are dwelling and business settlements of the affluent, upper income class of Lagos State. They (Ikoyi, Victoria Island and Lekki Peninsula) represent the cream of the most exclusive and expensive residential and business locations in the state. Victoria Island in particular is the main financial hub and business enclave of the trio with major 5 star hotels, expensive commercial real estates, exquisite private schools and a host of others. It inhabits most of the major indigenous and international corporations' headquarters. Although Ikoyi and Lekki Peninsula share similar characteristics with Victoria Island as exclusive commercial and business enclave, they are mainly residential settlements for the high-income elite and expatriates alike.

These two different districts (affluent and disadvantaged) are deliberately chosen for the study because of their obvious opposing socio-economic characteristics and contexts as mentioned above. In particular, the objective is to empirically measure how their varying socio-economic backgrounds might account for different outcomes in the performance of SMEs.

\subsubsection{Field Work Design}

For the purpose of this research, SMEs were included in the sample according to the following criteria:

- Significant use of ICT: The cases (firms) significantly support their business operations with ICT architecture (mobile phone, internet and/or personal computer), to the extent that if the ICT systems in their operations were to experience failure or malfunctioning, their business operations, productivity and overall performance would be negatively impacted.

- Pre-existing ICT exposure: The firms (especially those selected for the interview second phase of the research) have been in operations long before adopting/implementing ICT systems in their business dealings. This made it feasible empirically to track change/impact in business performance/productive efficiency occasioned by ICT adoption/usage.

- Similarity in ALL Respects: All drawn cases (firms) were similar in every known respect (business type, staff strength, knowledge/educational qualification of managers/employees, and so on), with the exception of differences in social contexts where they are embedded.

- The firms (cases) of interest (in equal number and size) originate from two different social contexts (upper, affluent community and poor, disadvantaged community). This ensures fair comparison on all grounds except the varying social contexts.

- Performing/Productive Business: Since the research interest was to explore ICT impact on business performance, the SMEs that were investigated were among the top, high-performing/productive entities in their industry 
Table 1: Sample

\begin{tabular}{|c|c|c|c|c|}
\hline $\begin{array}{c}\text { Research } \\
\text { Phase }\end{array}$ & $\begin{array}{c}\text { Affluent } \\
\text { Area }\end{array}$ & $\begin{array}{c}\text { Disadvantaged } \\
\text { Area }\end{array}$ & Sample Total & Research Method \\
\hline Phase 1 & 50 Firms & 50 Firms & 100 Firms & $\begin{array}{c}\text { Survey - } \\
\text { Structured_Questionnaire }\end{array}$ \\
\hline Phase 2 & 7 Firms & 7 Firms & 14 Firms & $\begin{array}{c}\text { In-depth Study - } \\
\text { Semi-structured } \\
\text { Interview }\end{array}$ \\
\hline
\end{tabular}

As shown in the table above, the study was undertaken in two phases: the first phase involved a survey of select Small and Medium enterprises operating in the affluent and disadvantaged areas of Lagos state, Nigeria. SMEs were selected by snowball sampling. Initial subjects (firms) that were suggested through referrals were also requested to nominate other businesses in their group (subject to meeting strict predefined eligibility criteria as stated in the previous page). Questionnaires were administered to 100 firms - 50 each from the affluent and disadvantaged areas, out of which 14 respondents, 7 each from the affluent and the disadvantaged areas were drawn for the second phase of the study. Therefore, the second phase of the research involved seven firms each (14 in total), drawn and interviewed from both the affluent and disadvantaged areas.

\subsection{Research Design}

The study examined ICT impact on SMEs business performance/productivity. A variant of longitudinal approach called 'Retrospective Panel Design' was employed. It used some recollection techniques and devices to enable respondents recollect and reconstruct the order and sequence of past experiences/activities. "We can work back from the present to the past or focus on "'anchor events"' and then question around these" (De Vaus, 2001, p.128). Very good and reliable data could be obtained by asking questions that explore significant milestones and memorable events in the respondents' life or business.

The non-probabilistic, purposive sampling technique that was adopted to recruit respondents for the study ensured only relevant respondents who were most likely to provide rich, quality and fruitful data in the context of examining causal relationship between the independent and dependent variables - (ICT impact and business performance) were recruited.

Also, this procedure was strategically adopted with a view to ensuring there is a match between research questions and sample of respondents. In other words, the relevance of respondents towards addressing research objectives and research questions guided sample recruitment (Bryman, 2008).

The sample were recruited in the same proportion from two communities in Lagos state, Nigeria, both with ICT access, but differentiated by socio-economic contexts or backgrounds - the upper, privileged class and the socio-economically-disadvantaged class.

Sample composition includes the following: SMEs who have been in business before ICT (internet-based, mobile and personal computer) diffusion in Nigeria, and whose businesses still subsist till date as well as firms who stared their businesses afterwards.

\subsection{Research Strategy}

The study adopted elements of both quantitative and qualitative paradigm - mixed method strategy. This was for the purpose of: triangulation (to enable the possibility for findings corroboration); offset (to allow potential weaknesses of methods associated with each strategy be offset by each other); completeness (to allow an in-depth, broad and comprehensive investigation as well as better understanding of phenomenon); credibility (to 
enhance the likelihood of results/findings integrity) and to be able to elicit diversity of views/responses from the sample (Bryman, 2008).

\section{LIMITATIONS OF THE STUDY AND WHAT THESE MEAN FOR FUTURE RESEARCH DIRECTION}

\subsection{Limitations in the Context of Research Coverage}

This research was limited to examining the ICT impact in the context of small and medium enterprises in Lagos State, Nigeria. Although small and medium businesses constitute a major sector in any economy and are very central to national development, other major stakeholders in socio-economic development such as: Large businesses/corporations, Multinationals, Nongovernmental organisations, government institutions as well as other private sectors operating in different socio-economic contexts need to be included in future investigations for a much deeper understanding of ICT impact in socio-economic process. Time and resource constraints did not allow for this extended scope.

Therefore, future research needs to accommodate these groups and note any emerging patterns and variations that could provide further insights into the relationship between technology and society. The following questions could guide future research direction:

1. What impact do ICTs have on business efficiency and performance; and to what extent does this improve organisational bottom-line?

2. In what specific business processes is ICT most effective; and how were these processes conducted before ICT?

3. What form of ICT is the most effective for facilitating business activities and why?

\subsection{Limitations in Research Methods}

This study used limited survey and comprehensive semi-structured interview methods to conduct an investigation on a purposively select small sample of small and medium businesses operating in both the affluent and disadvantaged districts of Lagos State, Nigeria concerning the impact of ICT (mobile telephony, computer/internet facilities) on their performance. The survey was only intended to generate a bird's eye view of respondents' opinions on the research questions, complemented with a more comprehensive semi-structure interview. Time and resource constraints were the main reasons for such a restricted sample size.

However, on reflection, it was thought that future research endeavour in this field should consider larger sample size that will be more representative, because a greater number of small and medium businesses now leverage the use of ICT to boost their business performance.

Also future research could consider additional research methods such as nonparticipant observation to further strengthen and corroborate survey and interview findings. Views of other departmental heads/representatives concerning their ICT usage experience could also be measured to provide further insights about the business impact of ICTs on organisational performance.

Thus, this research could serve as a pilot for future larger scale investigation. Future studies should also reflect a representation of different states in Nigeria to observe and document general patterns in the findings for policy considerations.

In view of the above shortcomings, the findings from this research cannot be generalised. However, the study contributes to deepening theoretical understanding of the relationship between technology and society in general and ICT impact in socio-economic process in particular. Besides, its contribution through analytical generalizations will also be valuable to policy design efforts. 


\section{RESULTS}

The research was conducted from the theoretical perspective that the relationship between communication technology and society is symbiotic - technology impacts society and factors within society also shape/influence technology choice and impact. The quantitative (survey) data obtained from the research went through a very basic manual descriptive analysis frequency and percentages. Participants' responses to each question were compared between the affluent and disadvantaged areas and patterns were noted.

\subsection{Survey Findings}

The major survey findings suggest that largest proportion of all the sampled firms (44.1\%) used the internet as the major communication technology medium. However, its usage is more evident (25.4\%) among firms operating in the affluent areas than those operating in the disadvantaged areas (18.6\%).

On the other hand, while mobile telephony closely follows the internet as the most used communication technology medium (37.3\%) among all the sample firms, it is much more common among companies operating in the disadvantaged areas (28.8\%) as against those in the affluent areas (8.5\%). All respondents in both affluent and disadvantaged areas (100\%) believe use of communication technology media improve business performance. This is also corroborated by works from (Rim Ben, Ayed Mouelhi, 2009; Esselar Steve et al., 2007; and Locke Stuart, 2004).

Survey findings also indicate that most of the respondents (67.8\%) in both the affluent and disadvantaged areas are of the opinion that the use of communication technology media has improved the performance of their business to a very great extent. Survey data also suggest that all 24 firms (8 from the affluent and 16 from the disadvantaged areas) whose business operations predated the advent of communication technology media, and are still in business till date believe use of communication technology media is making their firms perform better now compared to the period when they were not making use of any form of ICT to support their business activities.

Also, evidence suggests that local factors such as: 'level of education of customers' who live within the immediate operating environment of firms, and are served by such firms is a major factor that companies often consider in deciding which communication technology medium will be most cost-effective, relevant and appropriate to use in the course of their business activities. Other factors that are also considered by firms in this regard according to the survey findings are: Customers' purchasing power, customers' attitude to technology and the state of infrastructural support systems.

In conclusion, findings from the survey also suggest that largest proportion of all sampled firms (45.8\%) believe local factors influence their business performance to a great extent.

Table 2: Most used communication technology medium by the sampled companies

\begin{tabular}{|c|c|c|c|}
\hline $\begin{array}{c}\text { Communication } \\
\text { Medium }\end{array}$ & $\begin{array}{c}\text { Affluent } \\
\text { Area }\end{array}$ & $\begin{array}{c}\text { Disadvantaged } \\
\text { Area }\end{array}$ & Total \\
\hline Mobile telephone & $5 / 8.5 \%$ & $17 / 28.8 \%$ & $22 / 37.3 \%$ \\
\hline Personal computer & $2 / 3.4 \%$ & $3 / 5.1 \%$ & $5 / 8.5 \%$ \\
\hline Internet & $15 / 25.4 \%$ & $11 / 18.6 \%$ & $26 / 44.1 \%$ \\
\hline Intranet & $1 / 1.7 \%$ & 0 & $1 / 1.7 \%$ \\
\hline Video conferencing & 0 & 0 & 0 \\
\hline Email & $3 / 5.1 \%$ & $2 / 3.4 \%$ & $5 / 8.5 \%$ \\
\hline Sub-Total & $26 / 44.1 \%$ & $33 / 55.9 \%$ & $59 / 100 \%$ \\
\hline
\end{tabular}


Data from Table 2 shows that largest proportion of all the sampled firms (44.1\%) used the internet as the major communication technology medium. This figure is even more significant when added to the $8.5 \%$ of firms from both areas that use Email services, an internet-based facility as their major communication technology medium. However, the table depicts that internet usage as a major communication technology medium is more evident (25.4\%) among firms operating in the affluent areas than those in the disadvantaged areas (18.6\%).

By contrast, while mobile telephony closely follows the internet as the most used communication technology medium (37.3\%) among all the sampled companies, it is much more commonly used among firms operating in the disadvantaged areas (28.8\%) as against those in the affluent areas (8.5\%).

Table 3: Respondents' views on communication technology media as catalysts for business performance improvement

\begin{tabular}{|c|c|c|c|}
\hline $\begin{array}{c}\text { Respondents' } \\
\text { views }\end{array}$ & Affluent Area & $\begin{array}{c}\text { Disadvantaged } \\
\text { Area }\end{array}$ & Total \\
\hline Yes & $26 / 44.1 \%$ & $33 / 55.9 \%$ & $59 / 100 \%$ \\
\hline No & 0 & 0 & 0 \\
\hline Sub-Total & $26 / 44.1 \%$ & $33 / 55.9 \%$ & $59 / 100 \%$ \\
\hline
\end{tabular}

As shown in Table 3 above, all respondents in both the affluent and disadvantaged areas $(100 \%)$ are of the view that use of communication technology media improves their business performance. This perception is supported by empirical evidences from (Gomez, 2012; Aker et al., 2013; Aker and Mbiti, 2010; Rim, 2009; Esselar et. al, 2007; and Locke Stuart, 2004). Findings from their studies corroborate positive causal relationships between ICT and SMEs in terms of boosting productive efficiency, profitability and growth.

Table 4: Current state of performance of communication technology-driven companies compared to their pre-ICT experience

\begin{tabular}{|c|c|c|c|}
\hline $\begin{array}{c}\text { Company now } \\
\text { performing } \\
\text { better }\end{array}$ & Affluent Area & Disadvantaged Area & Total \\
\hline Yes & $8 / 33.3 \%$ & $16 / 66.7 \%$ & $24 / 100 \%$ \\
\hline No & 0 & 0 & 0 \\
\hline Sub-Total & $8 / 33.3 \%$ & $16 / 66.7 \%$ & $24 / 100 \%$ \\
\hline
\end{tabular}

Data from Table 4 above only relate to 24 firms (8 from the affluent and 16 from the disadvantaged areas) who had been in operation as business entities in the sampled population before the advent of communication technology media (internet, mobile telephone and personal computer), and are still operating as business concerns till date. All of them (100\%) believe use of communication technology media is making their firms perform better now compared to the period when they were not making use of any form of communication technology media to support their business activities. This is buttressed by empirical and theoretical research by (Gomez, 2012; Aker et al., 2013; Aker and Mbiti, 2010; Pyramid Research, UK, 2010; Thompson and Garbacz, 2007; Samuel Shah and Hadingham, 2005; Waverman, Mesch and Fuss, 2005; 2005; Jenson, 2007; Donner, 2004; Horst and Miller, 2006).

Evidence from these studies show that ICTs are potent tools in boosting productivity and enhancing workplace efficiency in the developing nations. In the same vein, 
(Papaioannou and Dimelis, 2007) reported in their study that there is an evidence of causality between ICT and organisational performance. In particular, they argued that there is a positive causal relationship between mobile technology and productive efficiency in the developing world. It is believed that people use mobile technology to facilitate business transactions, create business opportunities and also use it as a substitute for travel.

Table 5: Major influencing factor in local context

\begin{tabular}{|l|c|c|c|}
\hline Most Considered Local Factor & Affluent Area & $\begin{array}{c}\text { Disadvantaged } \\
\text { Area }\end{array}$ & Total \\
\hline Customers' level of education & $6 / 10.2 \%$ & $7 / 11.9 \%$ & $13 / 22 \%$ \\
\hline Customers' social status & $1 / 1.7 \%$ & 0 & $1 / 1.7 \%$ \\
\hline Customers' purchasing power & $6 / 10.2 \%$ & $2 / 3.4 \%$ & $8 / 13.6 \%$ \\
\hline Customers' attitude to technology & $7 / 11.9 \%$ & $4 / 6.8 \%$ & $11 / 18.6 \%$ \\
\hline Traffic situation & 0 & $3 / 5.1 \%$ & $3 / 5.1 \%$ \\
\hline Infrastructural support systems & $3 / 5.1 \%$ & $5 / 8.5 \%$ & $8 / 13.6 \%$ \\
\hline $\begin{array}{l}\text { ICT competencies/technical } \\
\text { knowledge of customers }\end{array}$ & $1 / 1.7 \%$ & $6 / 10.2 \%$ & $7 / 11.9 \%$ \\
\hline ICT technical knowledge of staff & 0 & 0 & 0 \\
\hline ICT competencies of staff & 0 & $4 / 6.8 \%$ & $4 / 6.8 \%$ \\
\hline $\begin{array}{l}\text { Type of ICT used by similar } \\
\text { companies }\end{array}$ & $1 / 1.7 \%$ & $2 / 3.4 \%$ & $3 / 5.1 \%$ \\
\hline Security situation & $1 / 1.7 \%$ & 0 & $1 / 1.7 \%$ \\
\hline None & 0 & 0 & 0 \\
\hline Sub-Total & $26 / 44.1 \%$ & $33 / 55.9 \%$ & $59 / 100 \%$ \\
\hline
\end{tabular}

Data from Table 5 shows that 'Level of Education of Customers' who live within the immediate operating environment of firms, and are served by such firms is a major factor that companies often consider in deciding which communication technology medium will be most cost-effective, relevant and appropriate to use in the course of their business activities. Largest proportion (22\%) of all sampled firms said the 'Level of Education of Customers' is a major factor that influences their choice of communication technology medium. This is followed by $18.6 \%$ of all respondents who are of the opinion that 'Customers' Attitude to Technology' within their areas of operation is a factor they consider most, as well as $13.6 \%$ of all sampled firms who expressed that they consider 'Customers' Purchasing Power' as a major factor in choosing which communication technology medium to use in their business activities. Some of the sampled firms (13.6\%) also view state of 'Infrastructural Support Systems' within their local operation areas as a major influencing factor in choice of useful and appropriate communication technology medium.

\subsection{Interview Findings}

This section presents a synthesis of major findings from both the semi-structured interview and the limited survey in the previous chapter. Highlights of the findings are captured below:

Findings from both the semi-structured interview and survey suggest that the adoption of ICT (mobile telephony, computer/and or internet facilities) signalled an improvement in business performance of studied firms in terms of operational cost reduction, sale/customer increase, business expansion, increase profitability, improve service quality/delivery, fraud reduction and general operational and administrative efficiency. It is also revealed that firms from different socio-economic backgrounds exhibit tendencies for using more of a particular form of ICT than others in their business engagements. Many of the businesses operating in the disadvantaged areas and having much of their customer base and other stakeholders 
within that vicinity tend to use more of mobile telephony than computer/internet facilities, while firms with more clientele in the affluent areas and operating from such locations use more computer/internet tools than mobile telephony for their business operations.

It is reported that nature of socio-economic peculiarities (level of education, income level, communication habits and level of sophistication) of clients in each operating area largely determine most effective and appropriate communication technology medium for business interaction. In addition, findings suggest that the nature of socio-economic peculiarities described above also shape and mediate the impact of ICT on business performance. In the affluent areas where most residents/clients are highly sophisticated, educated and financially-buoyant, impact of ICT on business performance appears to be more prominent and significant. The socio-economic peculiarities of the area seem to be catalysts to ICT-driven business performance. On the other hand, the prevailing low income level, high level of illiteracy and weak infrastructural support in the disadvantaged areas are shown to limit the extent of improvement communication technology could contribute to business performance of firms operating in the area.

\subsection{Thematic Data Analysis}

\subsubsection{ICT Impact on Performance}

Interview data shows that the firms (from both affluent and disadvantaged areas) interviewed experienced operational and administrative inefficiencies, sloppy communication, customers' dissatisfaction and restricted business expansion in their operations before deployment of Information Communication Technologies. They also endured numerous cases of fraud, resource wastages and inadequacy of requisite information for business operations.

According to Interviewee 6:

''Initially we run our operations manually, with lot of paperwork and time wastage. Marketing involved moving from place to place to woo potential customers. Customer as well as staff records were all manually documented and filed away in our filing room......tracking and retrieving staff or customer data was very tedious and time-consuming’’ (Interview 6 Transcript: p.2).

However, adoption of Information Communication Technologies in their businesses heralded an improvement and positive turn-around in terms of operational cost reduction, sale/customer increase, business expansion, increase profitability, improved service quality/delivery, fraud reduction and general operational and administrative efficiency. Some of the interviewees from both affluent and disadvantaged areas narrated their experience after adopting and deploying Information Communication Technologies thus:

Interviewee 1: 'I could interact with my staff, hold meeting through Skype and run the company's business from overseas. Right now am forwarding some templates I did about six years ago to some of my partners in Dubai and India. In the past, it would be impossible. So they have really enhanced our capacity. It has helped go more paperless. It has assisted in the areas of information and knowledge management system (Interview 1 Transcript: pg1). I don't think we can live without ICT now. Its like saying without aeroplane, you should go to Birmingham by foot, it is just not possible. It is unimaginable. We couldn't have functioned at our level now without ICT. The impact has been huge”, (Interview 1 Transcript: p.2). 
This is corroborated by the survey data in table 4 which only relate to 24 firms (8 from the affluent and 16 from the disadvantaged areas) who had been in operation as business entities in the sampled population before the advent of communication technology media (internet, mobile telephone and personal computer), and are still operating as business concerns till date. The survey finding revealed that all respondents $(100 \%)$ believe use of communication technology media is making their firms perform better now compared to the period when they were not making use of any form of communication technology media to support their business activities. The belief in the positive impact of Information

Communication Technologies on performance of small and medium enterprises is also supported by empirical evidences from (Rim Ben, Ayed Mouelhi, 2009; Esselar Steve et. al, 2007; and Locke Stuart, 2004). Findings from their studies corroborate positive causal relationships between ICT and small/medium businesses in terms of boosting productive efficiency, profitability and growth.

Empirical and theoretical research by (Gomez, 2012; Aker et al., 2013; Aker and Mbiti, 2010; Pyramid Research, UK, 2010; Thompson and Garbacz, 2007; Samuel et al., 2005; Waverman et al., 2005; Jenson, 2007; Donner, 2004; Horst and Miller, 2006) also buttress this argument. Evidences from these studies show that Information Communication Technologies (ICTs) are potent tools in boosting productivity and enhancing workplace efficiency in the developing nations.

\subsubsection{Mediation of Socio-Economic Contexts on ICT's Choice}

Data also shows that firms from different socio-economic settings exhibit tendencies for using more of a particular form of Information Communication Technology than others in their business engagements.

Interviewee 13: "We rely most on mobile telephone, especially for communication at operational level with staff as well as for strategic communication with our stakeholders such as our bankers with respect to getting update concerning our financial position for planning purposes. We also use mobile communication for regular contact with our customers parents of our students....' (Interview 13 Transcript: p.1).

In comparison, all the interviewed firms dealing with more clientele from the affluent areas and operating from such locations use more computer/internet tools than mobile telephone for their business operations. The following interview extracts explicitly state:

Interviewee 2: 'ICT, particularly internet is a tool of communication and research to us. It is the major medium we use to engage in business interaction with our clients in this area. We can't really do without it now'” (Interview 2 Transcript: p.2).

The evidences above for both the affluent and disadvantaged areas are supported by the survey finding in table 2 which depicts that internet usage as a major communication technology medium is more evident (25.4\%) among firms operating in the affluent areas than those in the disadvantaged areas (18.6\%) while mobile telephony is much more common among firms operating in the disadvantaged areas (28.8\%) as against those in the affluent areas $(8.5 \%)$ as the most used communication technology medium.

One plausible explanation for this is that nature of socio-economic peculiarities (level of education, income level, communication habit and level of sophistication) of clients in each operating area largely determine most effective and appropriate communication 
technology medium for business interactions. This is also corroborated by the survey finding in table 5 which shows that 'Level of Education of Customers' who live within the immediate operating environment of firms, and are served by such firms is a major factor that companies often consider in deciding which communication technology medium will be most costeffective, relevant and appropriate to use in the course of their business activities. The largest proportion (22\%) of all sampled firms said the 'Level of Education of Customers' is a major factor that influences their choice of communication technology medium, followed by $18.6 \%$ of all respondents who are of the opinion that 'Customers' Attitude to Technology' within their areas of operation is a factor they consider most, as well as $13.6 \%$ of all sampled firms who expressed that they consider 'Customers' Purchasing Power' as a major factor in choosing which communication technology medium to use in their business activities.

Regarding firms operating in the affluent areas:

Interviewee 1: "Most of our clients are professionals in their respective line of businesses, with comparable high level of sophistication and appreciation of ICT-driven tasks/work process. So we are guided by this understanding and always relate with them at that level with respect to business communication and relationship management. I have had business meeting with a client in Dubai through SKYPE and the outcome was very productive and mutuallyrewarding”' (Interview 1 Transcript: p.3).

Concerning firms operating in the disadvantaged areas:

Interviewee 13: 'It is more about literacy level. Being in that type of environment, not many people are very educated or well read. Second, the level of poverty - the income level is very low, so ability to explore communication facility or technology is limited. The other thing is weak infrastructural support such as electricity as well as the lifestyle of people around here. It is more of a noisy, loud lifestyle, so it is possible for you to have music being to the highest volume possible around you. These affect the adoption of ICT because you always feel how can I use ICT effectively in this type of environment? ... because if my customers don't have the literacy level to use internet, I can't use internet in communicating with them, because they won't understand it. Also if my customers don't have disposable income to procure desktop and connect to the internet, and I adopt internet, it is not going to be very useful for us. Also if there is no electricity to support the use of these things, it is not going to work. What is easiest for majority of our people/customer now is mobile communication and other facility you have on it such as 'text messaging'. That's what defines our choice/usage, that's what is supported by the environment where we operate. And that is why mobile telephony is what we deploy in great deal in our operations' (Interview 13 Transcript: p.4).

In the affluent area where most residents/clients are computer-literate, technologically-driven, highly educated and sophisticated with strong purchasing power, firms tend to adopt more of computer/internet facilities in their business activities and dealings than mobile telephony. However, in the disadvantaged areas that are often characterised by illiteracy, low income and weak infrastructural support, mobile telephony is 
the major medium often adopted by firms in business interactions with most clients in the areas.

\subsubsection{Mediation of Socio-Economic Contexts on ICT's Impact}

Interview data extracts also reveal that nature of socio-economic peculiarities of clients served by firms shape and mediate the impact of ICT on business performance. It is suggested that the extent to which communication technology media could boost their business performance is influenced greatly by factors within the local operating environment of firms.

In the affluent areas where most residents/clients/customers are highly sophisticated, educated and financially buoyant, impact of communication technology on business performance appears to be more prominent and significant. In other words, the socioeconomic peculiarities of the area seem to be catalysts to ICT-driven business performance.

According to one of the interviewees:

Interviewee 5: ' the level of sophistication of customers we serve informs our ICT deployment, which on the other hand helps us to meet their standard and taste, and then survive as a business entity. For example if don't have an internet or website that is constantly functioning and accessible, our performance will be affected because we deal with customers who always have access to the internet and might want to check a particular product anytime or make an online order to be delivered to them at a particular time’' (Interview 5 Transcript: p.3).

By contrast, the prevailing low income level and high level of illiteracy in the disadvantaged areas are shown to limit the extent of improvement communication technology could contribute to business performance of firms operating in the areas. This is expressed by some interviewees data extracts:

Interviewee 10: 'YYes. Because we could only go as far as what the parents could afford in terms of ICT deployment in the school. And apart from affecting students' learning outcomes in some respect, it even makes us less competitive as a school among our peers. You even desire parents to have computer at home that the children could use for their homework and so on. But the parents cannot afford it”' (Interview 10 Transcript: p.3).

\section{DISCUSSION AND CONCLUSIONS}

First, with respect to impact of communication technology on business performance, findings indicate that use of mobile telephony, computer and internet-based communication channels makes a significant contribution to the performance of the small and medium enterprises that were studied. Results also suggest that small and medium enterprises from different socioeconomic communities exhibit tendencies for using more of a particular form of communication technology medium than others in their business engagements. In addition, the interview and survey findings show that nature of socio-economic peculiarities (income level, level of education, level of sophistication and communication habit) of clients/customers served by firms also shape and moderate the impact of communication technology on business performance to a great extent.

The above empirical evidence from the study strongly supports the idea of a mutually influencing relationship between communication technology and society - communication 
technology positively impacts on the performance of small and medium firms, and existing socio-economic context/factors within the districts where the firms operate also influence the choice of communication technology and subsequently shape its impact on business performance.

\subsection{Contribution to the Literature}

This research contributes to a small (i.e Adewoye et al. 2012; Oluwatayo, 2012) but growing body of empirical investigations that examine the roles of ICT in the performance of small and medium businesses in Nigeria. Its general findings that ICT usage by SMEs positively impacts business performance in terms of cost reduction, enhanced productivity as well as improved revenue and profitability are also corroborated by evidences from Adewoye et al. (2012) and Oluwatayo (2012).

Further, it makes a direct contribution to a refinement and modification of Social Shaping Theory, which in its attempt to address the apparent neglect of social factors' influence on technology and the disproportionate attention some social scientists devote to the effect of technology on society - and from the perspective of technological determinism pays little attention to the valid arguments of technological determinism concerning the impacts/influence of technology on social context and relations. In addition, the study also contributes to advancement in the frontier of knowledge by deepening an understanding of the relationship between technology and society.

Also, this research presents a new perspective (Modified Social Shaping Theory) that would guide future research concerning the impact of ICTs in socio-economic change. Some of the previous works fail to also examine the peculiarities of social contexts in which technology is embedded, and how its impact might be shaped and moderated by such factors. In other words, hardly any previous studies has employed a modified Social Shaping framework for understanding ICTs impact in socio-economic change, particularly in regards to SMEs business performance. Instead, existing perspectives (such as technological determinism) that inform most ICTs impact studies are premised on the old paradigm assumption concerning socio-economic change - that development would be triggered across board, if technological architecture is copied and implemented wholesale.

Key findings in this research suggest a new, balanced perspective (modified Social Shaping Theory), and enrich theoretical discourse by acknowledging both social and technological factors in the debate. It suggests that the views expressed by some authors (Lerner, 1958; Pye, 1963; Ashby et al., 1980; Djamen et al., 1995; Lomas, 1995) that technological provision would generally impact or contribute to socio-economic advancement in developing society need to reflect varying contexts of infrastructure and socio-economic peculiarities of different communities, and how those might account for variation in socio-economic change.

Specifically, the modified Social Shaping Theory as a new model for understanding the relationship between technology and society is invaluable to researchers and policymakers in the following ways:

1. As an explanatory model to aid understanding and articulate the relationship between technology and society in socio-economic change process.

2. As an analytical tool to inform empirical investigations into the impact of ICTs in socio-economic development.

The findings lend support to the idea of a more symbiotic relationship between technology and society. It is argued that as communication technologies positively impact the performance of small and medium firms studied, existing socio-economic contexts/factors 
within the districts where the firms operate also influence the choice of communications technology, and significantly shape its impact on business performance.

\subsection{Contribution to Policy}

Findings suggest different outcomes in business performance of small and medium firms operating in different districts. High level of education, high level of sophistication and strong purchasing power of most clients/customers in the affluent areas are shown to be catalysts to ICT-driven business performance of firms operating in such communities. By contrast, the prevailing weak purchasing power and high rate of illiteracy that characterise disadvantaged districts served by studied firms are shown to limit the extent of improvement communication technology could contribute to business performance of firms in such areas.

It therefore appears that socio-economic factors such as illiteracy and poverty should be issues of great concern to government interested in using ICT to address socio-economic inequalities and engender even development. Other issue of concern to ICT policy designers should be relevance and appropriateness of ICTs services and content to varying and specific targets. The underlying cliché of the old development paradigm assumption that technology would leapfrog developing countries' socio-economic capabilities into the elite club of advanced knowledge-driven economies needs to give way to a more pragmatic, context and need-driven approach. In view of this, effective ICT for development policy should give serious considerations to the following:

First, ICT policy makers need to move beyond rhetoric and intensify real and concrete efforts at initiatives that would support eradication of mass illiteracy among the disadvantaged/poor communities. Findings suggest that high level of illiteracy among the disadvantaged districts served by the studied firms constitutes hindrance to improvement communication technology could contribute to business performance. The policy initiatives should encompass basic computer/internet training, information processing management and creation of more awareness about the potentials of ICT in improving the quality of life. These messages should be conveyed in local languages best understood by the target audience for ease of assimilation. The emphasis should be on imparting requisite knowledge that would make it easier for the disadvantaged/poor communities to be able to exploit the benefits of ICT to improve their quality of life.

Second, policy also needs to address the issues of un-affordability of computer/internet facility by the disadvantaged/poor communities. Findings indicate that prevailing weak purchasing power among the disadvantaged districts is one of the factors that restrain them from gaining access to computer/internet facilities, thereby limiting the extent firms could attempt in using communication technology to boost business performance. Policy makers would need to be more creative in addressing the digital divide occasioned by these factors.

\section{REFERENCES}

Adewoye, J.O. and Akanbi, T.A. (2012) Role of Information and Communication Technology Investment on the Profitability of Small and Medium Scale Industries - A Case Study of Sachet Water Companies in Oyo State, Nigeria. Journal of Emerging Trends in Economics and Management Sciences 3, 1, 64-71

Aker, J.C., Collier, P. and Vincente, P. (2013). Is Information Power? Using Mobile Phones and Free Newspapers During an Election in Mozambique: http://www.pedrovicente.org/cell.pdf.

Aker, J.C., and Mbiti, I. (2010). Mobile Phones and Economic Development in Africa, Journal of Economic Perspectives, 24, 3, 207-232. 
Ashby, J., Klees, S., Pachico, D. and Wells, S. (1980) Alternative Strategies in the Economic Analysis of Information/Education Projects. In McAnany, E.G. (ed.) Communications in the Rural Third World: The Role of Information in Development. New York: Praeger Publishers.

Barlow, J.P. (1998) Africa Rising: Everything you know about Africa is wrong. http://www.wired.com/wired/archive/6.01/barlow.html.

Barrantes, C.; Aileen, A.; Cesar, H. and Martin, C. (2012) The Impacts of the Use of Mobile Telephone Technology on the Productivity of Micro and Small Enterprises: An Explorative Study into the Carpentry and Cabinet-Making Sector in Villa El Salvador, Information Technology and International Development, 8, 4, 77-94.

Bijker, W. (1995) Socio-Historical Technology Studies. In Jasanoff et al., (eds.). Handbook of Science and Technology Studies. p. 229-256, Sage Publications: London

Bryman, A. (2008) Social Research Methods. New York: Oxford University Press

Broadband Commission For Digital Development Report (2013). http://www.itu.int/en/pages/default.aspx.

Burke, K. (2010) The Impact of Internet and ICT Use among SME Agribusiness Growers and Producers, Journal of Small Business and Entrepreneurship, 23, 2, 173-194.

Carmody, P. (2010). Globalization in Africa: Recolonization or Renaissance? Boulder, Co: Lynne Rhenner Publishers, Inc.

Charles, A.K., Ekong, U.O., Tolulope, F.I. and Ayodele, A.A. (2007) M-commerce Implementation in Nigeria: Trends and Issues. Journal of Internet Banking. 12, 2, 114.

Cockburn, C. and Furst-Dilic, R. (1994), Bringing Technology Home: Gender and Technology in a Changing Europe. Milton Keynes: Open University Press

De Vaus, D.A. (2001) Research Design in Social Research. London: Sage Publication.

Donner, J. (2004) Micro Entrepreneurs and Mobiles: An Exploration of the Uses of Mobile Phones by Small Business Owners in Rwanda. Information Technologies and International Development 2, 1, 1-21.

Djamen, J; Ramazani, D., and Somé, S. (1995) Electronic Networking in Africa: Emergence Towards the Internet. FID News Bulletin. 45, 7/8, 228-233.

Esselaar, S., Stork, C., Ndiwala, A., and Deen-Swarray, M. (2007) ICT Usage and its Impact on Profitability of SMEs in 13 African Countries. Information Technologies and International Development 4, 1, 87-100.

Etzo, S., and Collender, C. (2010). The Mobile Phone 'Revolution' in Africa: Rhetoric or Reality? African Affairs.109, 437, 659-668.

European Commission (2008) Making SMEs more competitive. http://ec.europa.eu/enterprise/sme/competitive_en.htm.

Evans, P.B. and Wurster, T.S. (1997) Strategy and the Economics of Information. Harvard Business Review.75, 5, 71-83.

Ezigbo, O. (2009) Nigeria: MDGs - Poverty Rate Rises to 75 Percent - UN. Thisday Newspaper. http://www.allafrica.com/stories/200902270161.html.

Frank, M. and Wallace, C. (2012) The Livelihood Outcomes of ICT Use in Microenterprises: The Case of South Africa, Electronic Journal of Information Systems in Developing Countries, 53, 1, 1-16.

Fuchs, C., and Horak, E. (2008). Africa and the Digital Divide. Telematics and Informatics. 25, 99-116.

Gillwald, A., and Stork, C. (2008). Towards Evidence-based ICT Policy and Regulation: ICT Access and Usage in Africa. http://www.eldis.org /go/home\&id=67783\&type=Document\#.VA5lsfmSy4k 
Global Systems Mobile Association (GMSA) and ATKEARNEY (2011). Africa Mobile Observatory 2011: Driving Economic and Social Development through Mobile Services. $\quad$ http://www.gsma.com/spectrum/wp-content/uploads/2011/12/AfricaMobile-Observatory-2011.pdf.

Golding, P., Donaldson, O., Tennant, V. and Black, K. (2008) An Analysis of Factors Affecting the Adoption of ICT by SMEs in Rural and Urban Jamaica. http://is2.lse.ac.uk/asp/aspecis/20080109.pdf.

Gomez, R. (2012). Users Perception of the Impact of Public Access Computing in Colombia: Libraries, Telecenters and Cybercafes. Information Technologies and International Development. 8, 3, 19-33.

Good, T. and Qureshi, S. (2009) Investigating the Effects of Microenterprise Access and Use of ICT through a Capability Lens: Implications for Global Development. Proceedings of the Second Annual SIG GlobalDev Workshop, Phoenix, USA

Hazbo, S., Arnela, C. and Chun-yan, H. (2008) ICT Adoption Model of Chinese SMEs. International Journal of Business Research. 44, 161-165.

Horst, H. and Miller, D. (2006) The Unpredictable Mobile Phone. http://www.ucl.ac.uk/anthropology/people/academic_staff/d_miller/.

Internet World Stats (2010) World Internet Users and Population Stats. http://www.internetworldstats.com/stats.htm.

Jensen, R. (2007) The Digital Provide: Information (Technology), Market Performance and Welfare in the South India Fishery Sector. Quarterly Journal of Economics. 122, 3, 879924.

Jelassi, T. (2010) ICT in Tunisia: A Strategic Lever for Building a Knowledge-based Economy, In Soumitra Dutta and Irene Mia (Editors): The Global Information Technology Report 2009 - 2010: ICT for Sustainability, World Economic Forum and INSEAD, March, 153-164.

Kamal, M. and Qureshi, S. ( 2009) An Approach to IT Adoption in Micro-Enterprises: Insights into Development . Proceedings of the Fourth Midwest United States Association for Information Systems Conference, Madison, USA

Lerner, D. (1958) The Passing of Traditional Society: Modernizing the Middle East. Glencoe, Illinois: The Free Press.

Locke, S. (2004) ICT Adoption and SME Growth in New Zealand. Journal of American Academy of Business, 4, 93-102.

Lamido, S. (2014) Corruption, Bane of Nigerian Economy, The Nation Newspaper, 07/03/2014

Lomas, P. (1995) Calling the Pacific: Pacific Communications and Computing Forum. Suva, Fiji: Islands Business Pacific Ltd.

Mackenzie D. and Wajcman J. (1999) The Social Shaping of Technology. Philadelphia: Open University Press

Nubi, T.O. and Omirin, M.M. (2006) Urban Violence, Land Rights and the Environment. Paper presented at the International Conference on Environmental Economics and Conflict Resolution, 25-28 July 2006, University of Lagos, Nigeria.

Okpaku, J. O. (2006). Leapfrogging into the Information Economy: Harnessing Information and Communication Technologies in Botswana, Mauritania and Tanzania. In Fox, L. and Liebenthal, R. (eds.). Attacking Africa's Poverty: Experience From the Ground. Washington, DC: World Bank.

Oluwatayo, I.B. (2012) Information and Communication Technologies as Drivers of Growth: Experience from Selected Small-Scale Businesses in Rural Southwest Nigeria. Department of Agricultural Economics, University of Ibadan, Nigeria. http://www.nai.uu.se/ecas-4/panels/141-156/panel-150/Isaac-Oluwatayo-Fullpaper.pdf 
Papaioannou, S.K. and Dimelis, S.P. (2007) Information Technology as a Factor of Economic Development: Evidence from Developed and Developing Countries. Economics of Innovation and New Technology, 16, 3, 179-194.

Pavic, S., Koh, S.C.L., Sampson, M. and Padmore, J. (2007) Could e-Business Create a Competitive Advantage in UK SMEs? Benchmarking: An International Journal. 14, 3, 320-351.

Peil, M. (1991) The City is the People. London: Belhaven Press.

Pilat, D. and Wolfl, A. (2004) The Productivity Paradox: Insights from Micro Data. OECD Economic Studies. (No. 38).

Ploch, L. (2011) Elections and Issues for Congress. Congressional Research Service. http://fpc.state.gov.documents/organisation.

Puri, J., Mechael, P., Cocmaciuc, R., Sloninsky, D., Modi, V., and Berg, M., (2010). A Study of the Connectivity in Millennium Villages in Africa. Paper Presented at $4^{\text {th }}$ International ICTD Conference. Royal Holloway, University of London.

Pye, L.W. (1963) Introduction, in Pye, L.W. (ed.) Communications and Political Development. New Jersey: Princeton University Press.

Roberts, F.O.N. and Oladeji, A. (2001) Resurgent Identity Crisis and Security Management in Lagos, Nigeria: Lessons for West African Cities. In Proceedings of International Conference on Security, Segregation and Social Networks in West African Cities, 19th-20th Centuries', Ibadan, Nigeria.

Roxana, B.C., Aileen, A. and Martin, C. (2011) The Impacts of the Use of Mobile Telephone Technology on the Productivity of Micro and Small Enterprises: An Exploratory Study into the Carpentry and Cabinet-Making Sector in Villa El Salvador. Information Technology and International Development. 8, 4, 77-94.

Rim, B.A.M. (2009) Impact of the Adoption of ICT on Firms' Efficiency in the Tunisian Manufacturing Sector. Economic Modelling 26, 5, 961-967.

Samuel, J., Shah, N. and Hadingham,W. (2007). Mobile Communications in South Africa, Tanzania, and Egypt: Results from Community and Business Surveys. Moving the Debate Forward: The Vodafone Policy Paper Series \#3.

Sproull, L. and Kiesler, S. (1991) Connections: New Ways of Working in the Networked Organization. Boston: MIT Press

Tella, S.A., Amaghionyeodiwe, A.L. and Adesoye, B.A. (2007) Telecommunication Infrastructure and Economic Growth: Evidence from Nigeria. Being a Paper Submitted for the UN-IDEP and AFEA Joint Conference on "Sector-led Growth in Africa and Implications for Development" to be held in Dakar, Senegal from November 8-11, $2007 \quad$ http://www.unidep.org/Release3/Conferences /Afea_2007/IDEP_07_17

Thompson, H.G. and Garbacz, C. (2007) Mobile, Fixed Line and Internet Service Effects on Global Productive Efficiency. Information Economics and Policy 19, 189-214.

Trading Economics (2011) Nigeria Population http://wwwtradingeconomics.com /nigeria/population

United Nations Development Programme (2007) The Role of Government in promoting ICT Access and Use by SMEs: Considerations for Public Policy. APDIP en-note 12/2007 http://www.apdp.net/apdipenote/12.pdf.

Van Dijk, J. (2006) The Network Society, $2^{\text {nd }}$ Edition, London: SAGE

Waverman, L., Meschi, M., and Fuss, M. (2007). The Impact of Telecoms on Economic Growth in Developing Nations. Moving the Debate Forward. The Vodafone Policy Paper Series \#3.

Williams, R., and Edge, D. (1996) The Social Shaping of Technology, Research Policy 25, 865-899. 
Winner, L. (1993) Open the Black Box and Find it Empty: Social Constructivism and the Philosophy of Technology. Science, Technology, and Human Values 18, 362-378.

World Bank (2013) Nigeria: Basic Economic Report, Report No 3341- UNI

World Bank Discussion Paper Series 246, Washington DC, World Bank

www.lagosstate.gov.ng (January, 2012) 